\title{
RFID based Airport No-Show Passenger Finding System
}

\author{
H. Jaithun Fameena ${ }^{1}$, Ms. S.Vithyalakshmi ${ }^{2}$ \\ Department of ECE, IFET College of Engineering, Villupuram, Tamilnadu, India ${ }^{1,2}$
}

\begin{abstract}
Due to tremendous growth in airline industries of recent years Air transport is as cheap as road transport such as buses, trains and car. In order to serve people better airport authorizes are expanding their infrastructures. Due to expansion of airport infrastructure the no-show passenger problem increased in recent year. To reduce the no show passenger problem in the airport and increase the efficiency of the public addressing system we designed a solution to the problem with RFID based boarding Ticket (Boarding Pass). In this project we are issuing RFID Tag based boarding ticket (Boarding Pass) to the passengers and reading the tag on different stages of airport through the RFID Reader kit. Then we send the final message to the passengers who are all not reached the final stage (i.e. Boarding Gate for Flight) by SMS as well as PA system by announcing particular Stage only or Send airport staff to pick up the particular passenger personally.
\end{abstract}

Keywords: RFID, No-Show Passenger, GSM, SMS, Boarding Pass, RFID Boarding Ticket.

\section{INTRODUCTION}

The main aim of this project is to reduce the no-show passenger in the departure boarding gate by using RFID based boarding ticket (Boarding Pass). Let us see what is meant by term "No-show Passenger"?

"No-show Passenger" means In Airport the passenger who check-in and received a boarding pass (ticket) has to clear immigration check and approach to departure gate. Most of the International airport in between immigration checks and departure gate there will be a duty-free shop. The passenger who received a boarding pass and not appeared in the departure gate in-time (specified time period normally 30mins) is considered as "No-show Passenger".

The main problem with the no-show passenger is airline authorities have to unload all baggage of the specified passenger. This procedure leads to unpack the container and remove specified baggage from the container and pack it again and load in to aircraft. Waste of time and sometimes delay in flight takeoff.

In order to address this issue we are using RFID based boarding pass (ticket) to find the no-show passenger location and inform them to arrive the boarding gate immediately by SMS ,PA System or arrange airport staff to collect them from the place and drop them in to boarding gate.

In our project we proposed to give RFID Tag based boarding pass (Ticket) and attached to the passport of the passenger in order to safeguard the boarding Pass. Most of the passengers take care of passport than any other things. In this way we can reduce the misplacement of boarding ticket of the passenger. Our solution is fully depending on boarding Pass if passenger misplaces the boarding pass we can find the approximate location of boarding pass but not the passenger.

In Our project we are keeping our RFID Reader kit in specified interval of distance all over the passage of the airport terminal as possible. Once the passenger cross the specific RFID Reader kit it reads tag information and send the SMS to central computer with reader Kit Id nothing but stage number or gate number, Time stamp and Passenger Tag ID information.

The central Computer receives the SMS and our customized program reads the SMS split the fields of the SMS data and store in the database table (Auto_ID, Passenger_TagID, Stage_ReaderID, and Times_tamp). Then we read the table information and group by Passenger_TagID first, order by Time_stamp and plot a graph with Stage_ReaderID info.

In this procedure we read all passengersTagID Information and process it to find the no-show passenger. The passengers who are all not reached the departure gate before specified time (30mins or 40mins) will be automatically sent SMS to their mobile number and PA system will announce the message requesting passenger to approach departure gate without further delay and in addition we can inform airport duty staff in particular stage to pick up the passenger to departure gate.

In departure gate we get number of passenger fail to reach by number of tickets issued minus number of passenger reached the departure gate. Then the system automatically sends SMS to no-show passenger. Through central computer we can find the no-show passenger location and announce through PA system in particular location. 


\section{EXISTING SYSTEM}

To find the no-show passenger in airport currently theyare using PA (Public Addressing) System to announce the passenger name and request to approach departure gate. This procedure will work well in small airport. Airport like Delhi international terminal, Dubai International Terminal etc. it is difficult to find the passenger because duty-free shops itself more than 1000metre long and to find the correct departure gate out of 50 and more gates again it is a difficult task and it will consume time. Sometimes in last hour they change the departure gate number.

\section{RELATED WORKS}

[1]. "Using Advanced RFID for Toll plaza Collection without Manpower"In this paperthey used the RFID based technology in automated tollgate system without the man power RFID technology to collect the toll fee.

[2]."Secure and Fast Missing RFID Tags Identification with Lightweight MAC and Rate less Coding"In this paper they used the RFID tag to find the missing object in the shop by using MAC and verify the stolen object in the shop.

[3]."RFID Based Missing Person Identification System"In this paper they used the RFID tag to find the missing senior citizen or physically/mentally disabled person in public gathering places.

\section{PROPOSED SYSTEM}

In order to overcome the problem we proposed a system with RFID-Tag based boarding ticket (Pass) in large airport to find the no-show passenger. Our proposed system will not eradicate the problem $100 \%$ but it will reduce the considerable amount of no-show passenger and help in reduction of expenses, manpower and delay in flight take-off etc. By using RFID Boarding Pass we will know exactly passenger's current location and announce the particular zone $\mathrm{PA}($ Public address) system to request passenger to approach departure gate or inform particular zone duty staff to pick up the passenger to departure gate.

\section{BLOCK DIAGRAM}

The components used in my project are RFID tag, RFID reader, Micro Controller, LCD Buzzer and GSM circuit and personal computer.

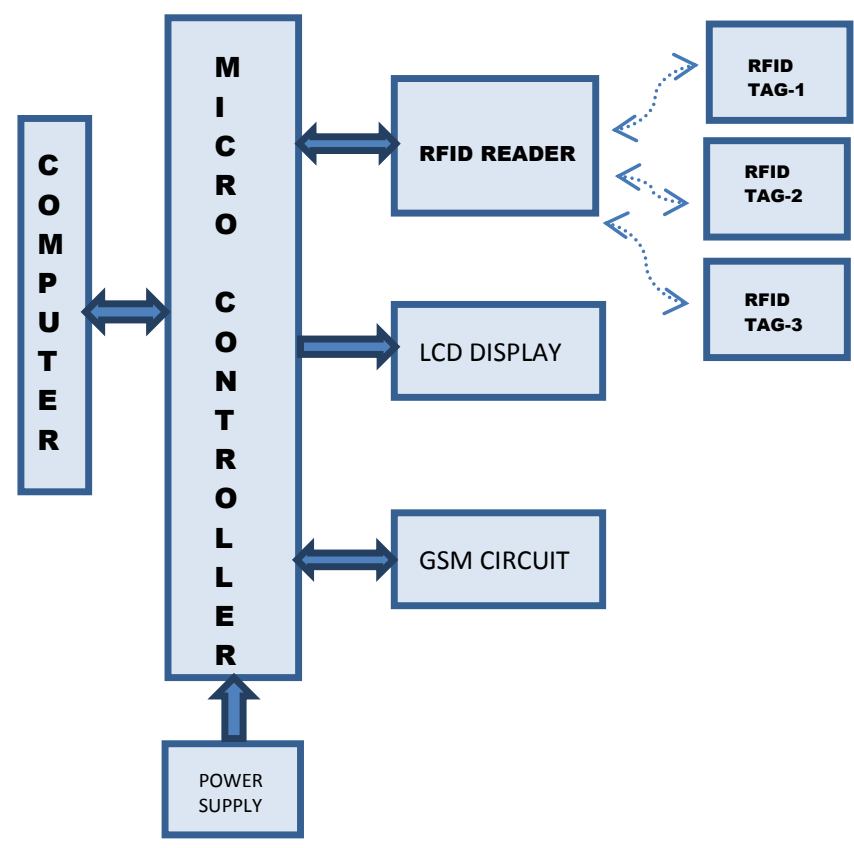

\section{A. RFID Tag:}

Radio Frequency IDentification is a form of wireless communication that uses radio waves (electromagnetic fields) to identify and track objects. Some of the features of the RFID are 
- Identify the items without direct Line Of Sight (LOS).

- Identify (Reads) many items simultaneously.

- It is aNear Field Communication(NFC) it reads from few centimeters to several metres.

There are three types of RFID namely Active,Passive,Battery Assisted Passive (BAP).

In Active type tag is build-in with battery source \& transceiver and operates with greater distance up to several meters. $(100 \mathrm{~m})$. In Passive type tag operates with smaller distance $(<3 \mathrm{~m})$ and there is no built-in battery. It is wirelessly powered through RF-Reader nearby(i.e. Passive tags draw power for chip through electromagnetic waves from RFID Readers). It is cheaper and compact. Active and Passive RFID operates in three different frequencies band namely Low Frequency(LF),High Frequency (HF) and Ultra High Frequency.

We are using Passive RFID tag with Low Frequency $125 \mathrm{KHz}$ for demo purpose but for practical situation you can use UHF with active RFID Tag. RFID Tag is embedded with transmitter, receiver, chip and antenna

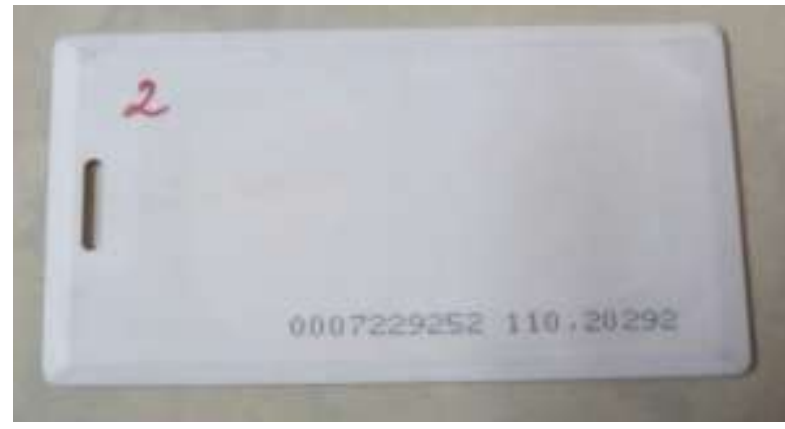

Figure1: RFID Passive tag.

\section{B. RFID Reader}

We used EM-18 RFID reader module. It is Low frequency RFID Reader and operates at $125 \mathrm{KHz}$. It contains on-chip antenna and work with $5 \mathrm{~V}$ source voltage. It reads the RF signal from the tag and converts in to identity data.

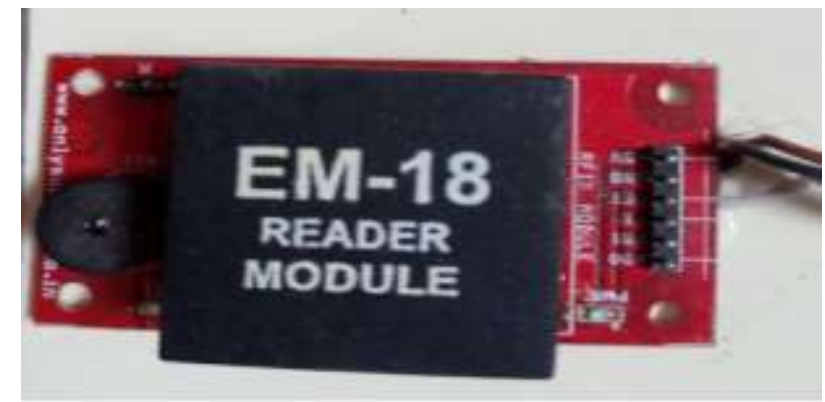

Figure2: RFID Reader EM-18

This identity data information is read by microcontroller through $\mathrm{Rx}$ and $\mathrm{Tx}$ pin interfaced between Microcontroller and RFID Reader EM-18.Then data is processed by Microcontroller and sent through GSM Module to central computer,passenger and LCD Display for status update.

\section{LCD Display.}

In this project we used 16x2 LCD display for status update. LCD 16x2 means 16 characters per line and it will support 2 lines. We used display for status update and to know whether our kit is working or not.

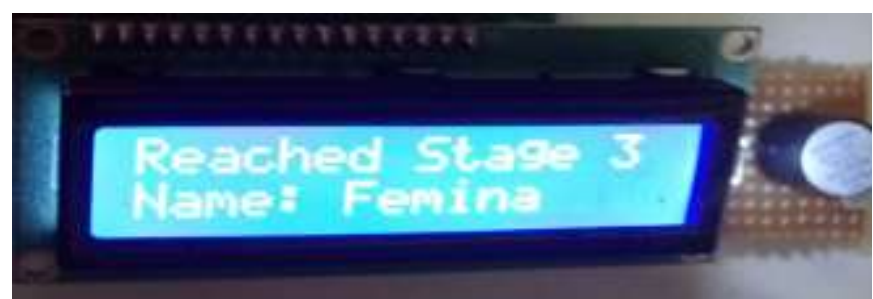

Figure3: 16x2 LCD Display 


\section{D.GSM Module:}

In Our Project we use GSM(Global System for Mobile Communication) Module to transfer the data collected by RFID Reader to central computer for further processing and to find the exact location of the no show passenger. Since we use many RF Reader kit in the passage of the airport. The data collected by each RFID Reader is sent by SMS (Short Message Service) to the central computer and we analyze the SMS and split the data in to different field and save in the database table to find the no-show passenger and further action. In One word we can tell GSM module is used for remote wireless data collection\& transfer process.

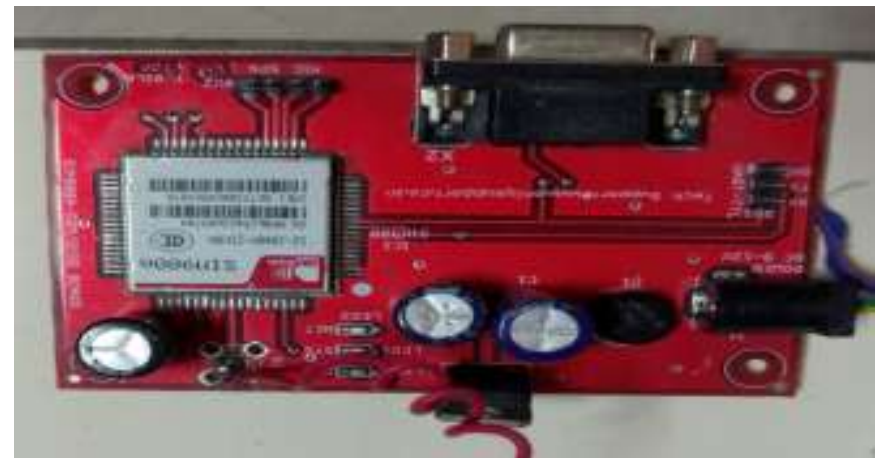

Figure4: GSM Module

\section{E.Atmega328P-PUMicrocontroller:}

The Atmega328P-PU is an 8 bit low power microcontroller board with flash memory and EEPROM. It has 14 digital input/output pins (of which 6 can be used as PWM outputs), 6 analog inputs, a $16 \mathrm{MHz}$ crystal oscillator, a USB connection, a power jack, an ICSP header, and a reset button. It contain all the feature to support microcontroller and power-up through USB 5V or external power supply (7V to $12 \mathrm{~V}) \mathrm{DC}$ adapter. Once we program the central computer mobile number microcontroller relay whatever tag RFID reader reads through GSM module in this way we save one computer cost.

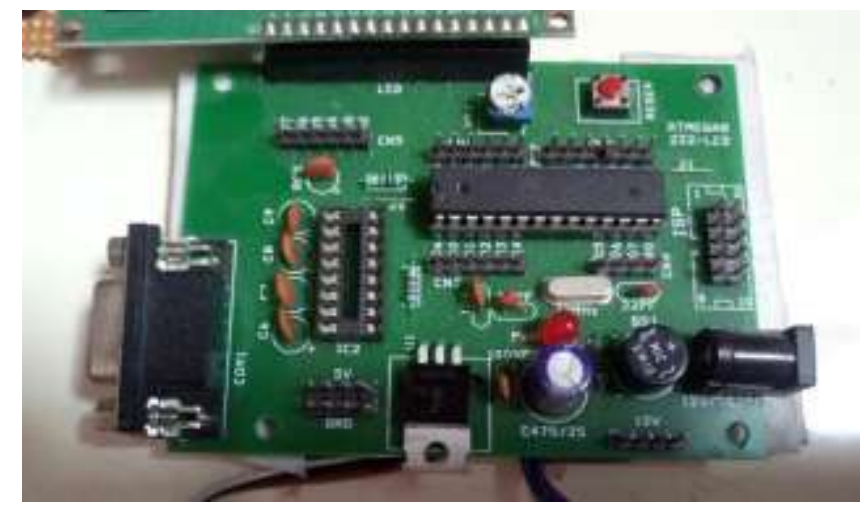

Figure5: Microcontroller board.

\section{TEST RESULT}

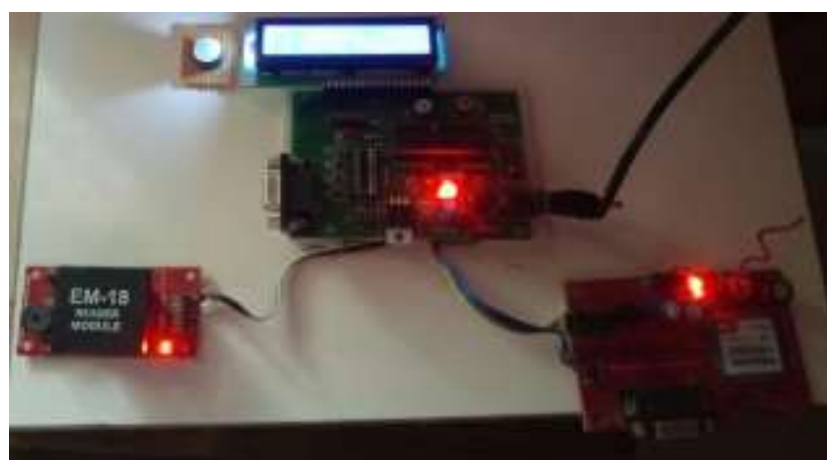

Figure6: Complete standalone Reader kit for one Stage 


\section{IJIREEICE \\ Vol. 5, Issue 5, May 2017}

We have tested the three RFID tags by passing in different stages and intentionally stopped one tag to cross all stages and we received a message in the tag mapped mobile number of the passenger. We repeated the test with two tags not crossing allstages we have received SMS in the two passengers mobile number and central computer. Whatever messages our kit sent out our central computer will get a copy of the SMS.The below image shows the different modules interface and working status of our project.

\section{CONCLUSION}

RFID Based Airport No-Show Passenger Finding System has been developed, tested and demonstrated the concept and it has sent the alert message to the passenger and concern authority. The salient feature of the project is low hardware cost, simple concept, simple design and easy maintenance and programming. If we implement this concept we can save huge resources in terms of money, manpower and time. Another advantage of this project is we can use the currently existing PA (Public Addressing) system efficiently.

\section{REFERENCES}

[1] S.VasanthaKumar,N.Prakash,R.Ranjitha,S.PSanthoskumar "Using Advanced RFID for Toll plaza Collection without Manpower", International Journal of Emerging Technologies in engineering research(IJETER),Volume4, Issue 3,March(2016)

[2]. Kentaroh Toyoda, Iwao Sasase "Secure and Fast Missing RFID Tags Identification with Lightweight MAC and Rate less Coding" IEEE ICCW, (2015)

[3]. SwarnaBaiArnikar, k.SitaRamaRao, G.Kalyani, D.Meena, M.Lalitha, K.Shirisha Seetasaikiran "RFID Based Missing Person Identification System" International Conference on Informatics Electronics\& vision (2014)

[4]. https://msdn.microsoft.com/en-us/library/aa479355.aspx

[5]. https://www.rfidjournal.com/discussions/thread?4621/4622

[6]. http://www.impinj.com/resources/about-rfid/how-do-rfid-systems-work/

[7]. https://www.arduino.cc/en/Main/Software

[8]. http://www.arduino.org/downloads

[9] http://www.aggsoft.com/serialdatalogger/tutorials/rfidllrptodatabase.htm 